\title{
Grain Contribution and Profit Deviation Measure in Heilongjiang Province Based on Factor Analysis
}

\author{
Sha Lou ${ }^{1, a^{*}}$ \\ ${ }^{1}$ Harbin University of Commerce, Harbin China 150028 \\ alousha1983@163.com
}

Keywords: Main grain producing areas; Grain contribution; Profit; Deviation; Factor analysis

\begin{abstract}
Heilongjiang is one of the major grain producing areas in China and we can clearly see its grain contributions. Based on grain contribution and profit deviation degree, the paper analyzes grain contribution and grain profit deviation among 13 main grain producing areas and clears its important status in Heilongjiang.
\end{abstract}

\section{Model Selection}

The part focuses on analyzing the deviation degree between grain contributions and grain profits. The ultimate goal is to compare their differences in different regions [1]. Grain contribution indicators and profit indicators can both be subdivided into a number of indicators. In order to analyze the problem objectively, it is necessary to define the indicator first, and then classify the objective data. Therefore, the paper chooses the factor analysis model, obtains two common factor indicators and gets the corresponding factor score.

\section{Variable Definitions}

According to two factors, the paper selects the variables. First, the paper selects the grain contribution factor which includes grain production scale, grain production and grain yield. Second, the paper selects the profit factor, which is expressed by the grain profit.

$\mathrm{X} 1$ grain production scale: The paper considers grain production scale as the grain sown area, which can intuitively express the grain production scale in each region [2]. Unit: thousand hectares

$\mathrm{X} 2$ grain yield: The grain yield refers to the total grain yield in a region that can visually reflect the contribution of grain yield in the region [3]. Unit: 10,000 tons

$\mathrm{X} 3$ commodity grain yield: The commodity grain yield is defined as the average number of grain which is sold by per capital in rural areas, which reflects the grain amount in a region [4]. Unit: $\mathrm{kg}$

$\mathrm{X} 4$ per mu grain profit: per mu of grain profit is the average profit earned on an acre of land and is the arithmetic average profits of the major food crops in the region. Unit: Yuan

\section{Data Selection}

According to the specific definition of the variable and the continuity of the data, the paper gets the following data through the query, collation and calculation of the China Statistical Yearbook in 2013 and the Compendium of Agricultural Products Costs and Revenue in 2014. Among them, there isn't the amount of per capita commodity grain in the China Statistical Yearbook in 2014, so the paper uses the data of the China Statistical Yearbook in 2013. 
Table 1 the data

\begin{tabular}{ccccc}
\hline region & $\begin{array}{l}\text { grain sown area } \\
\text { (thousand } \\
\text { hectares) }\end{array}$ & $\begin{array}{c}\text { total grain yield } \\
\text { (ten thousand } \\
\text { tons) }\end{array}$ & $\begin{array}{c}\text { per capita } \\
\text { commodity } \\
\text { grain yield } \\
(\mathrm{kg})\end{array}$ & $\begin{array}{l}\text { per mu of } \\
\text { profits }\end{array}$ \\
(Yuan) \\
Hebei & 6315.9 & 3365.0 & 604.4 & 84.2 \\
Inner Mongolia & 5617.3 & 2773.0 & 1128.8 & 183.6 \\
Liaoning & 3226.4 & 2195.6 & 1290.0 & 186.2 \\
Jilin & 4789.9 & 3551.0 & 2871.8 & 41.0 \\
Heilongjiang & 11564.4 & 6004.1 & 3457.8 & 102.3 \\
Jiangsu & 5360.8 & 3423.0 & 576.9 & 307.5 \\
Anhui & 6625.3 & 3279.6 & 761.3 & 164.6 \\
Jiangxi & 3690.9 & 2116.1 & 486.8 & 200.9 \\
Shandong & 7294.6 & 4528.2 & 633.0 & 202.7 \\
Henan & 10081.8 & 5713.7 & 670.6 & 136.6 \\
Hubei & 4258.4 & 2501.3 & 488.6 & 140.4 \\
Hunan & 4936.6 & 2925.7 & 200.6 & 43.2 \\
Sichuan & 6469.9 & 3387.1 & 97.6 & -26.2 \\
\hline
\end{tabular}

Data sources: "China Statistical Yearbook" and "Agricultural Product Cost and Revenue"

\section{Model Results Analysis}

The paper analyzes the principal components and factor scores of the selected data by using SPSS software, and finally the following specific results are obtained:

Through the test, the KOM value is 0.553 , which is greater than 0.5 and less than 1 . This indicates that the data meets the basic requirements of factor analysis. In addition, the significance value of Bartlett's test is 0 , much less than 0.05. This shows that the data passes the spherical test and can carry out factor analysis (see Table 2).

At the same time, the data extraction of grain sown area, total grain yield and per capita commodity grain yield and per mu grain profit are more ideal, it shows that the selected alternative factors is ideal and the main features of the data are retained.

Table 2 KMO and Bartlett's Test

\begin{tabular}{ccr}
\hline Kaiser-Meyer-Olkin Measure of Sampling Adequacy. & .553 \\
\hline Bartlett's Test of Sphericity & $\begin{array}{l}\text { Approx. Chi-Square } \\
\text { df }\end{array}$ & 26.993 \\
& Sig. & 6 \\
& Table 3 Communalities & .000 \\
\hline & Initial & Extraction \\
\hline grain sown area & 1.000 & 0.901 \\
total grain yield & 1.000 & 0.936 \\
per capita commodity & & 0.616 \\
grain yield & 1.000 & 0.987 \\
per mu of grain profits
\end{tabular}

Extraction Method: Principal Component Analysis.

According to the results of the model analysis, we can see that the four indexes of grain sown area, total grain yield, per capita commodity grain yield and per mu grain profit can be replaced by 2 common factors[5-7]. In the non-rotation phase, the replacement rate of the first common factor is 
$56.945 \%$ and the replacement rate of the second common factor is $24.085 \%$ for the original data. The cumulative substitution rate of the two common factors is $81.03 \%$ for the original data (see Table 4). This shows that substitution effect of the two public factors on the original relevant data is very obvious, and most of the characteristics are kept. In the non-rotation stage, the substitution effect of the first common factor on grain sown area, total grain yield and per capita commodity grain indicator is obvious, and the substitution efficiency is $93.9 \%, 95.3 \%$ and $64.4 \%$ respectively. The substitution effect of the second common factor on grain profit indicator is very obvious, and the replacement efficiency is $95.7 \%$. At the same time, the second common factor on the grain sown area, total grain yield and per capita commodity grain indicator also has a substitute effect.

Table 4 Total Variance Explained

\begin{tabular}{|c|c|c|c|c|c|c|c|c|c|}
\hline \multirow[b]{2}{*}{$\begin{array}{c}\text { Componen } \\
\mathrm{t}\end{array}$} & \multicolumn{3}{|c|}{ Initial Eigenvalues } & \multicolumn{3}{|c|}{$\begin{array}{c}\text { Extraction Sums of Squared } \\
\text { Loadings }\end{array}$} & \multicolumn{3}{|c|}{$\begin{array}{c}\text { Rotation Sums of Squared } \\
\text { Loadings }\end{array}$} \\
\hline & Total & $\begin{array}{c}\% \text { of } \\
\text { Varianc } \\
\mathrm{e}\end{array}$ & $\begin{array}{c}\text { Cumulative } \\
\%\end{array}$ & Total & $\begin{array}{c}\% \text { of } \\
\text { Varianc } \\
\mathrm{e}\end{array}$ & $\begin{array}{c}\text { Cumulative } \\
\%\end{array}$ & Total & $\begin{array}{c}\% \text { of } \\
\text { Varianc } \\
\mathrm{e}\end{array}$ & $\begin{array}{c}\text { Cumulative } \\
\%\end{array}$ \\
\hline 1 & $\begin{array}{c}2.27 \\
8\end{array}$ & 56.945 & 56.945 & $\begin{array}{c}2.27 \\
8\end{array}$ & 56.945 & 56.945 & $\begin{array}{c}2.23 \\
3\end{array}$ & 55.821 & 55.821 \\
\hline 2 & .963 & 24.085 & 81.030 & .963 & 24.085 & 81.030 & $\begin{array}{c}1.00 \\
8\end{array}$ & 25.209 & 81.030 \\
\hline $\begin{array}{l}3 \\
4\end{array}$ & $\begin{array}{l}.718 \\
.041\end{array}$ & $\begin{array}{c}17.951 \\
1.019\end{array}$ & $\begin{array}{c}98.981 \\
100.000\end{array}$ & & & & & & \\
\hline
\end{tabular}

In order to more significantly divide the common factor substitution effect, the variance maximum orthogonal rotation method is used to rotate the factor matrix. After the rotation, a new factor load matrix is obtained. At this time, the first common factor still has a significant substitution effect on grain sown area, total grain yield and per capita commodity grain yield, and the substitution efficiencies are $94.9 \%, 96.8 \%$ and $62.4 \%$ respectively. After the maximum orthogonal rotation of the variance, the substitution effect of the second public factor has further strengthened for grain profit, and its substitution efficiency is $99.9 \%$. Moreover, the alternative effect of the second common factor is further weakened for the other three indicators.

Table 5 Component Matrix

\begin{tabular}{ccc}
\hline indicators & \multicolumn{3}{c}{ Component } \\
\cline { 2 - 3 } & 1 & 2 \\
\hline grain sown area & 0.939 & 0.136 \\
total grain yield & 0.953 & 0.167 \\
per capita commodity grain & 0.644 & -0.046 \\
yield & -0.269 & 0.957 \\
\hline per mu grain profit & & \\
\hline
\end{tabular}

Extraction Method: Principal Component Analysis.

a 2 components extracted.

Table 6 Rotated Component Matrix

\begin{tabular}{ccc}
\hline indicators & \multicolumn{3}{c}{ Component } \\
\cline { 2 - 3 } & 0.949 & -0.040 \\
grain sown area & 0.968 & -0.013 \\
total grain yield & 0.624 & -0.164 \\
per capita commodity grain & -0.087 & 0.990 \\
yield & & \\
per mu grain profit & & \\
\hline
\end{tabular}

Extraction Method: Principal Component Analysis. Rotation Method: Varimax with Kaiser Normalization. a Rotation converged in 3 iteratens. 
The first common factor has a significant substitution effect on the grain sown area, the total grain yield and the per capita commodity grain yield [8]. The effect of the second common factor on the grain profit is obvious. According to different characteristics of the two common factors, the first common factor is named as yield factor which is expressed by F1 and the second common factor is named as profit factor which is represented by F2.

According to the analysis of the principal components, the paper combines the original 4 indicators into 2 common factors, and calculates the factor scores of the corresponding data with SPSS software, and gets the specific factor scores in 13 main grain producing areas [9].

From the first common factor score, there is a large gap in 13 main grain producing areas. The score is 2.5 in Heilongjiang, ranked the first in them. The score is 1.4 in Henan, ranked the second. The score is -1.05 , ranked the thirteenth. This shows that Heilongjiang has a significant advantage in grain yield, grain sown area and commodity grain yield, and the outstanding contributions and achievements made by Heilongiiang for the national grain production have been verified in the model.

Table 7 Factorial score

\begin{tabular}{ccccc}
\hline region & $F_{1}$ & rank & $F_{2}$ & rank \\
\hline Hebei & -0.18 & 7 & -0.56 & 10 \\
Inner Mongolia & -0.31 & 8 & 0.46 & 4 \\
Liaoning & -0.90 & 12 & 0.37 & 5 \\
Jilin & 0.18 & 4 & -1.30 & 12 \\
Heilongjiang & 2.50 & 1 & -0.29 & 9 \\
Jiangsu & -0.17 & 6 & 1.98 & 1 \\
Anhui & -0.05 & 5 & 0.35 & 6 \\
Jiangxi & -1.05 & 13 & 0.62 & 3 \\
Shandong & 0.52 & 3 & 0.91 & 2 \\
Henan & 1.4 & 2 & 0.31 & 7 \\
Hubei & -0.85 & 11 & -0.02 & 8 \\
Hunan & -0.73 & 10 & -1.06 & 11 \\
Sichuan & -0.37 & 9 & -1.76 & 13 \\
\hline
\end{tabular}

From the second common factor score, there is also a large gap in 13 main grain producing areas. The score is -0.29 in Heilongjiang, ranked the ninth in them. The score is 1.98 in Jiangsu, ranked the first. The score is 0.91 in Shandong, ranked the second. The score is -1.76 , ranked the last. Heilongjiang profit factor score lies in a downstream level among 13 main producing areas, which is 2.27 lower than the first place in Jiangsu, is 1.2 lower than the second place in Shandong and is 2.05 higher than the last one in Sichuan. This shows that there is a big disadvantage in Heilongjiang in terms of grain profit which is significantly lower than most of the main producing areas.

\section{Conclusions}

On the whole, the specific features of Heilongiiang are as follows: the output factor score is high and the profit factor score is low. In the yield factor score, Heilongjiang ranks the first in 13 main producing areas, is much higher than the other major producing areas. The profit factor score only ranks the ninth, which has a large gap with other provinces [10]. Jilin and Henan have the same problem with higher yield factors. Compared with its grain yield status, it can be said that the level of grain profit in Heilongjiang is obviously at a low level. 


\section{Acknowledgments}

This research was financially supported by the the National Social Science Fund (16CJY053).

\section{References}

[1] D.H. Zhang: Financial support, scale management and farmers' income in Heilongjiang Province. (China Fortune Press, China 2015).

[2] Z.F. Chen: Regional Economic Review, (2017) No.2, P.115-123.

[3] B. Bravo-Uretaa, D. Sol'is, H. Cocchi and R.E. Quiroga: Agricultural Economics, (2006) No.35, P.267-276.

[4] P. M. Kostov, S. McErlean, and J. Moss: Food Policy, Vol. 33 (2008), No.5, P. 397-405.

[5] B. Kirwan: Journal of Political Economy, (2009) No. 117: 138-164.

[6] D.L. Carter and R.D. Berg: Journal of Soil and Water Conservation, Vol.46, (1991), No.2, P.139-142.

[7] A.A. Adesina, D. Mbila, and G.B. Nkamleu: Agriculture Ecosystems and Environment, 2000, No. 80, P. 255-265.

[8] O. Mertz, R.L. Wadley and A.E. Christensen: Agricultural Systems. (2005), No.85, P. 209-215.

[9] M. Marrit, H. Hengsdijk, and J. Wolf: China Agricultural Systems. (2007), No.11, P.1-10

[10] C.G. Concepción, M. Candelaria and C. Pestano-Gabino: Journal of Social Sciences, Vol.4 (2008), No.2, P.88-97. 